\title{
Effect of diet supplemented with two sources of antioxidants as feed additives on growth indices and internal organs of broiler-chicken
}

*Imaseun, J. A. and Ijeh, O. A.

Animal Physiology and Reproduction Unit of the

Department of Animal science, University of Benin, Benin-city Nigeria.

*Corresponding author: james.imasuen@gmail.com : +2348073604853

\section{Abstract}

Growth indices and the internal organs of 125 broilers (four weeks of age) were assessed in order to study the effect of Zingiber officinale (Ginger), Piper nigrum (Black Pepper) and Vitamin $C$ as feed additives in their diet. Ginger, Black pepper and Vitamin $C$ powder were administered at the level of $50 \mathrm{~g} / 10 \mathrm{~kg}$ of feed. The broilers were randomly allotted to five treatments: T1 (no antioxidant), T2 (0.5\% ginger powder), T3 (0.5\% black pepper powder), T4 (0.25\% ginger $+0.25 \%$ black pepper), T5 (0.5\% Vitamin C) in a completely randomized design. The results Obtained showed that the Average weight gain ( $g$ ) was significantly $(P<0.05)$ higher in T2 (33.31) compared to the other treatment groups. The Wing length (cm) of T1 (9.58), T3 (10.21) and T5 (9.47) were not significantly different from each other but was significantly $(P<0.05)$ higher than T2 (8.68) and T5 (7.16). The breast width $(\mathrm{cm})$, chest length (cm), total feed intake $(\mathrm{g})$, average daily feed intake $(\mathrm{g})$ and feed conversion ratio $(\mathrm{g})$ of the broiler birds were not influenced by the dietary antioxidant feed additives. The weights (g) of the Kidney, Liver, Gizzard, Heart, and Spleen in all treatment groups were not significantly different from each other. Effect on kidney function test reveals the results of potassium $(\mathrm{Mmol} / \mathrm{L})$ to be significantly $(P<0.05)$ higher (4.27) in T1 compared to the other treatment groups, with the lowest value of potassium content in T5 (2.70). Creatinine $(\mathrm{mg} / \mathrm{dL})$ content varied among treatment groups with T4 significantly $(P<0.05)$ higher (0.32) compared to other treatment groups. Liver function test showed AST(IU/L) content in T4 (190.33) to be significantly $(P<0.05)$ higher compared to other treatment groups. ALP (IU/L) was lowest in T1 (127.67) and T5 (320.00) was significantly $(P<0.05)$ higher compared to other treatment groups. Ginger supplemented diet increased feed intake and Vitamin C supplemented diet yielded the best feed conversion ratio.

Keywords: Broiler, Ginger, Black pepper, Vitamin C, Feed, Growth.

\section{Introduction}

Growth promoters or feed additives are molecules that are added at low rate to animal feeds without changing considerably their composition (Admad et al., 2006). They speed up the growth and consequently increase the body size and weight of animals (Biovet, 2005). Among all growth promoters, the most commonly used are antibiotics, although their use is decreasing towards total extinction (Biovet, 2005). Some growth promoter's act as pro-nutrients because of the role they play in enhancing the physiological and microbiological status of the animals. Pronutrients are substances that could have the same effect as antibiotic feed additives and are defined as micro ingredients included in the formulation of animal feeds with physiological and microbiological functions different from any other nutrient (Biovet, 2005). Many active ingredients from plants are considered as pro-nutrients and are recently been tried in animal feeds (Biovet, 2005). Pro-nutrients are also sometimes referred to as phytogenic feed additives. Phytogenic feed additives are plant-derived products used in animal 


\section{Feed additives on growth indices and internal organs of broiler-chicken}

feeding to improve their performance. This class of feed additives has recently gained increasing interest, especially for use in swine and poultry. This appears to be strongly driven by a complete ban on most of the antibiotic feed additives within the European Union in 2006 (Windisch et al., 2008).

Zingiber officinale is a perennial plant, commonly known as ginger. Ginger may act as a pro- nutrient because of the vast active ingredients it has been reported to contain. Herbs Hands Healing (2011) reported that ginger contains a protein digesting enzyme (Zingibain) which is believed to improve digestion as well as kill parasites and their eggs. It was also reported to enhance antibacterial and antiinflammatory actions.

Another natural antioxidant of interest is the black pepper (Piper nigrum), Its role in the male reproductive organ and fertility of mice (Kumar et al., 2008) has been well documented. In connection with reproductive function, black pepper extracts effects on human and animals seem to contradict each other as well (Kpomah et al., 2012). Artificial sources of antioxidant also play help in broilers physiological performance. Vitamin $\mathrm{C}$ is one of the nutritional factors important in layering hen performance and egg quality. It is mandatory in maintaining normal body metabolic activities and to meet physiological requirements as well as exhibit anti-oxidative or pro-oxidative effects (Mc Dowell, 1989). Synthetic antioxidants such as butylated hydroxyl toluene and butylated hydroxyl lanisole have been approved to control lipid oxidation in foods, but recently cancer restricts their use (Okada et al., 1990). Therefore, the need to research into an alternative to synthetic antioxidants becomes imperative. Antioxidant inclusion is shown to be very vital to improve growth performance in commercial poultry. It was known that increase of live weight gain of broilers was as a result of the supplementation of herbal extracts rich in antioxidant (Man war et al., 2005). According to Lin et al. (2003), dried black pepper has strong antibacterial, anti- ulcer, analgesic, antioxidant and hypocholesterolaemic activities. With this knowledge of antioxidant effect in the animal body, and paucity of information regarding their influence on broilers, it is imperative to evaluate the effects of these natural sources of antioxidant (Ginger and Black Pepper) on the growth and performance of broiler chicken.

\section{Materials and methods \\ Experimental animal, location and management}

A total of 125 broiler chicks were brooded with coal heat source for 4weeks and were fed a $24 \%$ protein broiler starter commercial ration ad libitum. The diet was changed to commercial finisher and the experimental treatment was incorporated into it and was fed from 4 weeks of age till $9^{\text {th }}$ week of age. The experiment was conducted at the Poultry unit of the University of Benin Teaching and Research Farm, Benin City, Edo State, Nigeria. The farm lies between latitude 6.50 " $\mathrm{N}$ of the equator and longitude 5.40 and $6^{\circ} \mathrm{E}$ of Greenwich meridian, with mean annual temperature of $33.54^{\circ} \mathrm{C}$. The area has an average annual rain fall and relative humidity of $2000 \mathrm{~mm}$ and $72.5 \%$ respectively (Google earth, 2016). The birds were randomly allocated to five (5) treatments having 25 birds per treatment in a Completely Randomized Design (CRD). Body weight and feed consumption were determined by measurement weekly and feed conversion ratio was also calculated. The birds were vaccinated against 


\section{Imaseun and Ijeh}

Newcastle and Gumboro diseases according to schedule and other medications when necessary. The birds were provided feed and water ad libitum throughout the period of the experiment.

\section{Experimental feed additives}

Fresh matured ginger roots and dried black pepper were purchased in a commercial market in Benin, Edo State, Nigeria. The ginger bulbs were washed in clean water, sliced, dried and milled into ginger powder and the dried black pepper was milled into pepper powder before being incorporated into the formulated diet. The vitamin $\mathrm{C}$ $(10 \mathrm{mg})$ was obtained from a pharmaceutical store and was ground into powder.

Thus we have the following treatments: Treatment 1: Control group - (No antioxidant). Treatment 2: Ginger powder(Zingiber officinale). Treatment 3: Black pepper-(Pipernigrum).

Treatment 4: Black pepper + Ginger powder - (25g Black pepper and $25 \mathrm{~g}$ Ginger). Treatment 5: Vitamin $\mathrm{C}$ (ascorbic acid)

Each treatment diet was supplemented at $50 \mathrm{~g} / 10 \mathrm{~kg}$ feed. The proximate analysis of the experimental diet is shown in Table 1

Table 1: Proximate analysis of test diet included the test ingredients, ginger, black pepper and vitamin $C$

\begin{tabular}{llllllll}
\hline Samples & $\begin{array}{l}\text { Moisture } \\
\text { contend }\end{array}$ & $\begin{array}{l}\text { Dry } \\
\text { matter }\end{array}$ & Ash & Fat & Fibre & Protein & NFE \\
\hline T1 & 8.356 & 91.643 & 8.260 & 10.260 & 5.423 & 19.833 & 47.866 \\
T2 & 9.273 & 89.726 & 7.750 & 10.550 & 4.273 & 21.00 & 46.153 \\
T3 & 9.130 & 89.870 & 8.320 & 10.330 & 4.423 & 19.250 & 47.546 \\
T4 & 8.066 & 89.933 & 8.456 & 10.460 & 5.756 & 18.250 & 49.010 \\
T5 & 8.726 & 89.273 & 8.136 & 10.936 & 5.823 & 19.416 & 41.756 \\
\hline
\end{tabular}

Wing length, breast width and chest circumference measurement

The wing length and breast width was measured once every week from the $5^{\text {th }}$ week till the $9^{\text {th }}$ week .In taking the measurement a measuring tape was used. In taking the wing length the tape was placed at the beginning of the wing and extended to the tip of the wing, in taking the breast width the tape was place from the joint of one wing to the joint of the other wing. In taking the chest circumference the tape was placed round the chest.

\section{Carcass evaluation}

At the end of the experiment, fifteen (15) birds were selected. Diet and water were withdrawn from the broiler chickens overnight 12 hours before being slaughtered. A total of 15 birds were slaughtered (i.e. 3 per treatment pen). The birds were weighed just before slaughtering, and after slaughtering. The carcass was opened and the organs were weighed (heart, spleen, kidney, liver and the gizzard-with and without its content). The carcass was weighed without the internal organs and again after de-feathering with hot water. All values were recorded.

\section{Liver Function Test (LFT)}

The serum for LFT was refrigerated at $20^{\circ} \mathrm{C}$ for 8 hours. The enzymes AST (Asparate transaminase) ALP (Alkaline phosphate), A L T (Alanine aminotransferease) were analyzed using the Bechman Synchron LX20 system (2001) which uses an enzymatic rate method to measure enzyme activities in serum. The rate of enzymatic activities is monitored in $\mathrm{a} b \mathrm{~s}$ o r b a n c of $340 \mathrm{n} \mathrm{m}$ spectrophotometrically. The absorbance is 
directly proportional to the enzyme activity in the sample. The Total and conjugated (direct) bilirubin concentrations were analyzed using the modified JendrassikGrof (2008) method which uses the DBI Flex ${ }^{\circledR}$ reagent cartridge.

\section{Kidney Function Test (KFT)}

The serum biochemical analyzed for kidney function includes: Urea, Sodium, Potassium, Bicarbonate $\left(\mathrm{HCO}_{3}\right)$, Creatinine and chlorine. Urea was analyzed by spectrophotometric measurement of diacetylmonoximere action as described by Wybenga et al. (1971), Potassium and Sodium by Flame photometric method as described by Valle and Thiers (1965). Bicarbonate $\left(\mathrm{HCO}_{3}\right)$ was determined by titrimetric method as described by Segal (1955). Chlorine was determined by Chloridometric method described by Cotlove (1961) and Creatinine by Spectrophotometric determination of Alkaline Creatinine picrate reaction (Jaffe reaction) as described by Taussky (1954).

\section{Statistical analysis}

The data obtained was subjected to statistical analysis of variance (ANOVA) procedure of GenStat $17^{\text {th }}$ edition at $5 \%$ probability level and Duncan multiple range test option of the same statistical software was used to separate the treatment means.

\section{Results}

The results of the effect of two sources of antioxidant on the growth indices of broiler chickens are as shown in Table2. Weight gain of birds on T2 (2099.01g) was significantly ( $p$ ? 0.05) higher than those in other, treatment group. The values for weight gain ranged from $1810.05 \mathrm{~g}$ in the control to $2099.01 \mathrm{~g}$ in T2. The values for feed intake ranged from $57.46 \mathrm{~g}$ in the Control to $63.96 \mathrm{~g}$ inT2. Vitamin C diet had the best feed conversion ratio of 1.87 . The values ranged from 1.87 in control to 2.00 in T4. The values obtained from the breast width $(\mathrm{cm})$ ranged from 8.85 in $\mathrm{T} 5$ to 10.15 in the T2. The Wing length $(\mathrm{cm})$ of T1 (9.58), T3 (10.21) and T5 (9.47) were not significantly different from each other but was significantly $(\mathrm{P}<0.05)$ higher than $\mathrm{T} 2$ (8.68) and T5 (7.16). Values for chest circumference $(\mathrm{cm})$ ranged from 8.15 in T2 to 10.10 in the control.

Table 2: Effect of two sources of dietary antioxidant on growth indices of broiler chickens

\begin{tabular}{lllllll}
\hline Parameters & T1 & T2 & T3 & T4 & T5 & 土SEM \\
\hline Initial wt $(\mathrm{g})$ & 45.13 & 45.01 & 45.50 & 45.13 & 42.04 & 1.83 \\
Final wt $(\mathrm{g})$ & 1855.18 & 2144.02 & 2025.61 & 1990.29 & 2027.17 & 9.85 \\
Wt gain $(\mathrm{g})$ & $1810.05^{\mathrm{c}}$ & $2099.01^{\mathrm{a}}$ & $1980.11^{\mathrm{b}}$ & $1945.16^{\mathrm{b}}$ & $1985.13^{\mathrm{b}}$ & 9.73 \\
AWG $(\mathrm{g})$ & $28.73^{\mathrm{c}}$ & $33.31^{\mathrm{a}}$ & $31.43^{\mathrm{b}}$ & $31.51^{\mathrm{b}}$ & $31.51^{\mathrm{b}}$ & 0.086 \\
Breast wdt $(\mathrm{cm})$ & 9.15 & 10.15 & 9.20 & 9.35 & 8.85 & 0.760 \\
Wing Lth $(\mathrm{cm})$ & $9.58^{\mathrm{a}}$ & $8.68^{\mathrm{ab}}$ & $10.21^{\mathrm{a}}$ & $7.16^{\mathrm{b}}$ & $9.47^{\mathrm{a}}$ & 0.689 \\
Chest cm & 10.10 & 8.15 & 9.40 & 8.68 & 9.95 & 0.911 \\
TFI $(\mathrm{g})$ & 3620.11 & 4030.09 & 3793.06 & 3841.41 & 3731.55 & 9.75 \\
ADFL $(\mathrm{g})$ & 57.46 & 63.96 & 60.20 & 60.97 & 59.23 & 0.11 \\
FCR & 2.00 & 1.92 & 1.92 & 2.00 & 1.87 & 0.468 \\
\hline
\end{tabular}

a,b,c; means in the same row with different superscript are significantly different $(\mathrm{p}<0.05)$

T1: Control (No antioxidant), T2: (0.5\% Ginger), T3: (0.5\% Black pepper), T4: (0.25\%Ginger and $0.25 \%$ black pepper), and T5: (0.5\% Vitamin C).

Keywords Wt: weight; AWG: Average weight gain. Wdt: width $(\mathrm{cm})$; Lth: length $(\mathrm{cm})$; cm: Circumference $(\mathrm{cm})$; ADFL: Average daily feed intake (g) TFI: Total feed intake (g); FCR: Feed conversion ratio 
The results of the effect of two dietary sources of antioxidant on the organ weight of broiler chickens are shown in Table 3. The Kidney weight ranged from $0.55 \mathrm{~g}$ in $\mathrm{T} 2$ to $0.65 \mathrm{~g}$ in T4. The weight of the liver varied from $2.29 \mathrm{~g}$ in the control diet to $2.83 \mathrm{~g}$ in T3. The weight of the gizzard with its content ranged from $2.22 \mathrm{~g}$ T 5 to $2.82 \mathrm{~g}$ in
T3. The weight of the gizzard without its content ranged from $1.74 \mathrm{~g}$ T5 to $2.01 \mathrm{~g}$ in $\mathrm{T} 1$. The weight of the heart varied from $0.40 \mathrm{~g}$ in T2 to $0.51 \mathrm{~g}$ in T3. The weight of the spleen ranged from $0.29 \mathrm{~g}$ in $\mathrm{T} 1$ to $0.20 \mathrm{~g}$ in T5. The weights (g) of the Kidney, Liver, Gizzard, Heart, and Spleen in all treatment groups were not significantly different from each other.

Table 3: Effect of two dietary sources of antioxidant on the organ weight of broiler chickens

\begin{tabular}{lllllll}
\hline Parameters $(\mathrm{g})$ & $\mathrm{T} 1$ & $\mathrm{~T} 2$ & $\mathrm{~T} 3$ & $\mathrm{~T} 4$ & $\mathrm{~T} 5$ & \pm SEM \\
\hline Kidney & 0.60 & 0.55 & 0.62 & 0.65 & 0.63 & 0.6975 \\
Liver & 2.29 & 2.73 & 2.83 & 2.50 & 2.58 & 0.4459 \\
Gizzard wc & 2.75 & 2.73 & 2.82 & 2.65 & 2.75 & 0.5054 \\
Gizzard woc & 2.01 & 1.84 & 1.92 & 1.77 & 1.74 & 0.415 \\
Heart & 0.45 & 0.40 & 0.51 & 0.48 & 0.41 & 0.0833 \\
Spleen & 0.29 & 0.21 & 0.28 & 0.24 & 0.20 & 0.0473 \\
\hline
\end{tabular}

a,b,c; means in the same row with different superscript are significantly different $(\mathrm{p}<0.05)$

T1: Control (No antioxidant), T2: (0.5\% Ginger), T3: (0.5\% Black pepper), T4: (0.25\%Ginger and 0.25\% black pepper), and T5: (0.5\% Vitamin C); WC: with content, WOC: without content.

The result of the effect of two sources of dietary antioxidant on kidney function test is as shown in Table 4. The urea content ranged from $5.57 \mathrm{mg} / \mathrm{dl}$ in the Control to $6.67 \mathrm{mg} / \mathrm{dl}$ in T4. The sodium content varied from $142.67 \mathrm{mmol} / \mathrm{L}$ in the control to $145.00 \mathrm{mmol} / \mathrm{L}$ in $\mathrm{T} 2$. The value recorded for $\mathrm{HCO}_{3} \mathrm{Mmol} / \mathrm{L}$ ranged from 21.67 T3 to 27.67 in T4. The chlorine Mmol/L content varied from 105.33 in $\mathrm{T} 5$ to 109.67 in T1.
The value obtained for glucose ranged from $162.00 \mathrm{mmol} / \mathrm{L}$ in $\mathrm{T} 3$ to $186.50 \mathrm{Mmol} / \mathrm{L}$ in $\mathrm{T} 2$. The results of potassium $(\mathrm{Mmol} / \mathrm{L})$ was significantly $(\mathrm{P}<0.05)$ higher $(4.27)$ in $\mathrm{T} 1$ compared to the other treatment groups, with the lowest value of potassium content in T5 (2.70). Creatinine $(\mathrm{mg} / \mathrm{dl})$ content varied among treatment groups with T4 significantly $(\mathrm{P}<0.05)$ higher $(0.32)$ compared to other treatment groups.

Table 4: Effect of two sources of dietary antioxidant on kidney function test

\begin{tabular}{lllllll}
\hline Parameters & T1 & T2 & T3 & T4 & T5 & 土SEM \\
\hline Urea(mg/dl) & 5.57 & 6.67 & 6.67 & 6.00 & 6.00 & 0.730 \\
Sodium (mmol/L) & 142.67 & 145.00 & 144.67 & 143.33 & 144.67 & 1.814 \\
Potassium (mmol/L) & $4.27^{\mathrm{a}}$ & $3.80^{\mathrm{ab}}$ & $3.37^{\mathrm{ab}}$ & $3.10^{\mathrm{b}}$ & $2.70^{\mathrm{b}}$ & 0.344 \\
HCO3 (mmol/L) & 23.33 & 22.67 & 21.67 & 27.67 & 27.00 & 2.599 \\
Chlorine (mmol/L) & 109.67 & 108.67 & 108.67 & 106.33 & 105.33 & 3.451 \\
Creatinine (mg/dl) & $0.27^{\mathrm{b}}$ & $0.28^{\mathrm{ab}}$ & $0.27^{\mathrm{b}}$ & $0.32^{\mathrm{a}}$ & $0.29^{\mathrm{ab}}$ & 0.013 \\
\hline
\end{tabular}

$\mathrm{a}, \mathrm{b}, \mathrm{c} ;$ means in the same row with different superscript are significantly different $(\mathrm{p}<0.05)$

T1: Control (No antioxidant), T2: $(0.5 \%$ Ginger), T3: (0.5\% Black pepper), T4: ( $0.25 \%$ Ginger and $0.25 \%$ black pepper), and T5: $(0.5 \%$ Vitamin $\mathrm{C}), \mathrm{HCO}_{3}$ (Bicarbonate). The results on the effect of two dietary sources of antioxidant on Liver function test are shown in Table 5. Total bilirubin ranged from $0.27 \mathrm{mg} / \mathrm{dl}$ in $\mathrm{T} 4$ to $0.37 \mathrm{mg} / \mathrm{dl}$ in the control. Conjugated bulirubin varied from $0.13 \mathrm{mg} / \mathrm{dl}$ in $\mathrm{T} 4$ to $0.20 \mathrm{mg} / \mathrm{dl}$ in the Control. The AST (IU/L) values in T2 and T4 was 174.67 and 190.33 


\section{Feed additives on growth indices and internal organs of broiler-chicken}

respectively and both were significantly $(\mathrm{P}<0.05)$ higher than T4. ALP (IU/L) was lowest in T1 (127.67) and T5 (320.00) was significantly $(\mathrm{P}<0.05)$ higher compared to other treatment groups.

Table 5: Effect of two sources of dietary antioxidant on liver function test

\begin{tabular}{lllllll}
\hline Parameters & T1 & T2 & T3 & T4 & T5 & \pm SEM \\
\hline $\begin{array}{l}\text { Total } \\
\begin{array}{l}\text { Bilirubin(mg/dl) } \\
\text { Conjugated }\end{array}\end{array}$ & 0.37 & 0.37 & 0.33 & 0.27 & 0.33 & 0.033 \\
$\begin{array}{l}\text { Bilirubin } \\
\text { (mg/dl) }\end{array}$ & 0.20 & 0.17 & 0.17 & 0.13 & 0.17 & 0.030 \\
AST(IU/L) & $148.33^{\mathrm{c}}$ & $174.67^{\mathrm{b}}$ & $136.7^{\mathrm{c}}$ & $190.33^{\mathrm{a}}$ & $140.67^{\mathrm{c}}$ & 4.310 \\
ALT(IU/L) & 91.67 & 75.00 & 72.33 & 94.33 & 89.00 & 7.262 \\
ALP(IU/L) & $127.67^{\mathrm{c}}$ & $190.67^{\mathrm{b}}$ & $210.67^{\mathrm{b}}$ & $297.00^{\mathrm{b}}$ & $320.00^{\mathrm{a}}$ & 18.159 \\
\hline
\end{tabular}

$\mathrm{a}, \mathrm{b}, \mathrm{c}$; means in the same row with different superscript are significantly different $(\mathrm{p}<0.05)$ ALP $=$ Alkaline phosphate, $\mathrm{ALT}=$ Alanine amino transferease, $\mathrm{AST}=$ Asparate transaminase.

T1: Control (no antioxidant), T2: (0.5\% Ginger), T3: (0.5\% Black pepper), T4: (0.25\% Ginger and 0.25\% black pepper), and T5: (0.5\% Vitamin C)

\section{Discussion}

The weight gain of broilers was significantly increased by addition of natural (ginger and black pepper) and synthetic (Vitamin C) sources of antioxidant feed additives. There were tendencies for broilers fed these sources of antioxidants to grow faster than control as numerically higher values of wing length were observed in T3 when compared with the control. All treatments recorded higher values of breast width as compared to Control. T2 had a higher chest circumference and ADFI. Diets with additives recorded higher values for live weight as compared with the Control. T2 and T3 had higher values of bled weight as compared to the Control. These numerical increases observed could be due to the fact that herbal plants (ginger and black pepper) and vitamin $\mathrm{C}$ may provide some compounds that help increase digestion and absorption of some nutrients in these experimental diets and also aiding in antibacterial activities which may lead to improved growth of the birds (El-tazi et al., 2014; Hosseni, 2011). Galib et al. (2011) reported that the addition of black pepper in a high activity of piperazier citrate which can affect the flow of digestive juices across the stomach. Also, sometimes addition of this antioxidant could result in reduction in total feed intake as observed with $\mathrm{T} 2$ and T3. This may be due to their taste hence reducing feed intake (Hosseini, 2011). Differences were not observed in the organ yield (kidney, liver, gizzard with content, gizzard without content, heart and spleen) of the treatment groups when compared with the control. These results were in accordance with those reported by AlKassie et al. (2011) and El-tazi et al. (2014) were addition of different levels of black pepper had no influence in the edible giblets (liver, heart and gizzard).

Aspartate amino transferase (AST) content in birds on Ginger diet and ginger/black pepper diet were significantly increased compared to the control. Vit. C diet, Ginger diet and black pepper diet recorded lower values of alanine aminotransferase (ALT) when compared with the control. A similar situation was observed by Emadi and Kermanshahi (2007). Fernandez et al., 
(1994) induced liver damage using aflatoxin in broilers and layers and observed an increase in serum ALT. Therefore, the reduction in ALT of Vit C, ginger and ginger/black pepper diet can be an indication of better liver function.

Effect on kidney function test reveals the results of serum potassium to be significantly higher (4.27) in T1 compared to the other treatment groups, with the lowest value of potassium content in T5 (2.70). Creatinine content varied among treatment groups with T4 significantly higher (0.32) compared to other treatment groups. Potassium is an essential electrolyte, which is a mineral that the body needs to function correctly. This mineral is particularly important for the nerves and muscles. All muscles need potassium, including the heart. Healthy kidneys flush excess potassium out of the body. In extreme cases, high potassium can cause paralysis and heart problems ( ht t p : / / w w w.healthline.com retrieved15/5/2017). The level of Serum Potassium in control group fell within the normal range $(4.60-6.50 \pm 0.41 \mathrm{Mmol} / 1)$ in Chicken as described by Albritton (1952) but was influenced in treatment groups with additives. The reduction in potassium level could affect muscle tone and cause fatigue to the animals (http://www.healthline.comretrieved 15/5/2017), if this be the case, diet supplemented with feed material llike soy bean rich in potassium may be added to boost potassium level for the proper functioning of the cells, muscles and the heart. The creatinine levels across treatment groups were lower than the normal range $(0.90-1.85 \pm 0.3 \mathrm{mg} / \mathrm{dl})$ for normal chicken as described by Albritton (1952). These low levels could signify that the kidney functioned properly in caring away waste like creatinine out of the body, it could also indicate low muscle mass as may be caused by low serum potassium and as a result of plant-based diet (www.livestrong.com).

\section{Conclusion}

In conclusion, it can be ascertained that ginger and black pepper naturally can be used as growth promoters instead of artificial growth promoters since, increase in the live body weight and feed efficiency was observed. This study goes further to prove that they are better alternative compared to the synthetic growth promoters as there was no observed growth retardation by the ginger and black pepper. It can also be insinuated that ginger or black pepper containing diets respectively improved kidney function by clearing out creatinine in the blood. The low creatinine level reflects low creatine which is normally high in animal protein and when eaten by humans tend to increase creatinine level in their blood system. This reflects that birds fed with diets containing ginger or black pepper will be healthy for human consumption.

\section{References}

Admad, N., Sulaiman, S., Mukti, N. A., Murad, N. A., Hamid, N. A. A. and Yusuf, Y. A. M. 2006. Effects of ginger extract (Zingiber officnale roscoe) on antioxidant status of heap to caranoma induced rats. Malays J. biochem Mol. Boil 14:7-12

Al-kassie, G. A. M., Mamdooh, A. M., AlNasraw, S. and Ajeena, J. 2011. Use of black pepper (piper nigrum) as feed additive in broiler diet. Research opinions in animal and veterinary science 1(3):169-173.

Albritton A. B. 1952. Standard Values in blood. Philadelphia, W.B. Saunders Beckman Synchron LX 
systems chemistry Information Manual, 2001.

Biovet, S. A. 2005. The Intensive Production and the Spreading of High Productivity Genetic

Stocks have conditioned the common use of chemical Substances Known as "Growth Promoters". www.the pig site.com/articles

Cotlove, E. 1961. Standard methods of Clinical Biochemistry, vol 3, Edited by Seligso D.New York, Academic Press.

El-Tazi, M. A., Safa, Mukhtar, M. A., Mohamed, K. A. and Tabidi, M. H. 2014. Effect of using black pepper as natural feed additives, on performance and carcass quality of broiler chickens. Glo Adv Res. J. Agric. Sci.3 (4):113-118.

Emadi, M. and Kermanshahi, H. 2007. Effect of turmeric rhizome powder on the activity of some blood enzymes in broiler chickens. Int. Poult. Sci.6:48-51.

Fermandez, A., Verde, M. T., Gascon, M., Ramos, J. J., Gomez, J., Luco, D. F and Chavez, G. 1994. Variation of clinical biochemical parameters of laying hens and broiler chicks fed aflatoxin containing feed. Avian pathol 23:37-47.

Galib, A., Al-kassie, M., Mamdooh, A., Al-Nassawi, M. and Saba, J. A. 2001. Use of black pepper (piper nigrum) as feed additives in broilers diet. Roars. 1(3):169-173.

Google Earth. 2016. http//earth google.com

Herbs Hands Healing Ltd. 2011. Traditional Western Herbal Product. Ginger Extracts from ina Nutshell 'Ginger' by Jill Rosemary Davies. www.herbs-handshealing.co.uk.Retrieved July 12,
2011.

Hosseini, M. N. 2011. Comparison of using different level of black pepper with probioticon performance and serum composition on broiler chicken .J. basic Appl. Sci. Res 11: 2425-2428.

J e n frassik-Grof. 2008 . D B I Flex ${ }^{\circledR}$ reagent. In Jacobs \& DeMott laboratory Test hand book (2001) lexi-comp

Kpomah, E. D., Uwakwe, A. and Abbey, B. W. 2012. Aphrodisiac studies of diherbl mixture of zauthoxylum lepureriguill. And perand pipper

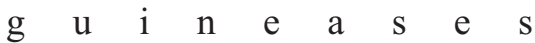
chumachandthonn.onmadle wristar rat.Global j.Res.med. Plant indigen.med.1:381-390.

Kumar, P. P., Pankaj, P. K., Raina, V. S., Roy, B., Mohanty, T. K. and Mishra, A. 2008. Study of Relationship of Age, Testicular, B i o m e try and Semen Characteristics. In: Pankaj ,P.K., Mishra, A. and Jain, R. Veterinary Practitioner, 9(1): 83-88.

Lin, C. C., WU., S. J., Chang, C. H. and Nu, L. T. 2003. Antioxidant activity of cinnanomum cassia.Phyto Research 17:726-730.

Manwar, S. J. Thirumurugan, P., Konwar, D. and Karna, D. K. 2005. Effect of Azadirachta indica leaf powder supplementation on broiler performance. Indian Veterinary Journal 84:159-162

McDowell, L. R. 1989. Vitamins in animal nutrition comparative aspects to human nutrition.

Academic press Ltd. LondonU.K

Okada, Y., Okajima, H. and Konishi, H. 1990. Antioxidant effect of naturally occurring Furanfatty acid on oxidation of Linoleic acid in 


\section{Imaseun and Ijeh}

aqueous dispersion. J. Am oil Chem Soc. $67: 858$

Segal, M. A. 1955. A rapid electrotitrimetric method for determining $\mathrm{CO}_{2}$ combining power in Plasma or serum, Am JClin Pathol 25:1212

Taussky H. H. 1954. A micro colorimetric determination of creatinine in urin by Jaffe reaction. J. Biol.Chem 208:853

Valle, B. L. and Thiers, R. E. 1965. Flame photometry in treatise on Analytical Chemistry.

Kalthofff I,I., Elving P.J (Eds). Newyork, Inter Science, Vol 6, p3463
Windisch, W., Schedle, K., Plitzner, C. and Kroismayr, A. 2008. Use of phytogenic products as feed additives for swine and poultry. Journal of Animal Science. Vol.86 n o. 14 s u p p 1. E 140 E148.Jas.fass.org/cgi/content/shor t/86/14_suppl/sE140.

Wybenga, D. R., Digiorio, J. and Pileggi, V. J. 1971. Manual and automated methods of Urea nitrogen measurement in whole serum. Clin Chem 17:891

ht tp://www.healthline.com retrieved $15 / 5 / 2017$

h t t p : // w w w . 1 ives trong. co m retrieved15/5/2017.

Received: $5^{\text {th }}$ November, 2017 Accepted: $20^{\text {th }}$ February, 2018 